\title{
The Perennial Fascination with Decline and Collapse: The Scientific Paper Driving People into Therapy
}

ISSN: 2637-7659

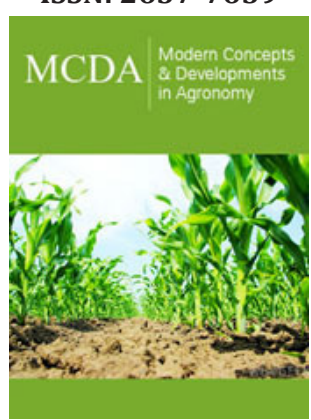

*Corresponding author: Dr. Ted Lefroy, Adjunct Professor, Tasmanian Institute of Agriculture, University of Tasmania, Researcher ID: J-7144-2014, Australia

Submission: 眥 November 11, 2020

Published: 留 November 13, 2020

Volume 7 - Issue 4

How to cite this article: Ted Lefroy The Perennial Fascination with Decline and Collapse: The Scientific Paper Driving People into Therapy. Mod Concep Dev Agrono. 7(4). MCDA. 000667. 2020. DOI: 10.31031/MCDA.2020.07.000667

Copyright@ Dr. Ted Lefroy, This article is distributed under the terms of the Creative Commons Attribution 4.0 International License, which permits unrestricted use and redistribution provided that the original author and source are credited.

\section{Ted Lefroy*}

Adjunct Professor, Tasmanian Institute of Agriculture, University of Tasmania, Australia

\section{Opinion}

It is not often that an academic paper is downloaded over 600,000 times. Even rarer that one is described as 'the scientific paper sending people into therapy' [1]. Such is the social phenomenon triggered by the paper Deep Adaptation: A map for navigating climate tragedy [2], published privately after it was rejected by the journal Sustainability Accounting, Management and Policy [3]. What follows is an agronomist's attempt to understand the basis for the paper's claim that we face 'inevitable near-term societal collapse' due to '... uncontrollable levels of climate change bringing starvation, destruction, migration, disease, and war' [1].

In the paper's preamble we learn it resulted from a 2017 sabbatical spent reviewing the latest climate science. And in a letter to the journal editor attached as a postscript, the author responds to a reviewer who questioned whether the climate data supported the paper's argument by stating that section is '...the core of the paper as everything then flows from the conclusions of that analysis' [2]. Several aspects of that analysis warrant a closer look.

First, throughout the paper the term non-linear is used to imply unstoppable or runaway climate change. Non-linear means change in the output of a system that is not proportional to change in the inputs. It implies nothing about the direction or speed of change or the feasibility of human intervention or management. When Gavin Schmidt, Director of the NASA Goddard Institute for Space Studies, was asked to comment on an earlier version he replied 'This is nonsense. Non-linearity (which is ubiquitous) is not synonymous with 'runaway' climate change'. To which the author responded 'Verdict: No clarification or correction. Adding a reference to the new findings from scientists will be useful in future publications' [4].

The new findings included in the revised version are drawn from an article on climate tipping points [5] which, the paper claims, indicate that we 'have tipped into self-reinforcing and irreversible change' [2]. What those authors actually said was 'If damaging tipping cascades can occur and a global tipping point cannot be ruled out, then this is an existential threat to civilization' [5]. The qualifier 'if' is important as the phenomenon of tipping cascades is hypothetical, which is why the paper was published as a comment, not a research paper. On global tipping points, others have argued 'The global human enterprise is driving large-scale changes in most components of the Earth system, but in a haphazard fashion, with responses often being weakly connected or transmitted slowly at a cross-continental scale' making it '...implausible that the planet, or indeed most of its component systems, are primed to tip irreversibly to a radically different state that is inhospitable' [6].

Second, the prediction that global tipping points will lead to inevitable near term societal collapse rests largely on two phenomenon, Arctic ice melt and methane release. Both rely on a few, selected sources. In the case of the Arctic ice melt, the work of one scientist whose predictions have not eventuated [7]. In the case of methane release, it relies on the clathrate gun hypothesis first proposed in 2003 that has since been challenged in multiple reviews [8].

Third on crop yields, the paper notes that the IPCC has estimated that climate change has reduced growth in crop yields by $1-2 \%$ per decade over the past century. This needs to 
be seen in the context of yield increases in the major crops of 300$800 \%$ over the same period. In the UK $\sim 300 \%$ for oats and barley, $\sim 400 \%$ for wheat and potatoes and $\sim 800 \%$ for sugar beet; in the USA, $\sim 500 \%$ for corn [9]. Climate change is real and is having an impact on agriculture, but the major challenge now is not yield but equitable access. The major challenge for the future is declining investment, particularly in plant breeding and agronomy.

Fourth, on declining fish stocks, the paper states that ocean acidification 'degrades the base of the marine food web, thereby reducing the ability of fish populations to reproduce themselves across the globe' [2]. The paper cited in support of this statement mentions acidification once, in the first paragraph of the introduction, as a process that 'may impact the productivity of fish stock' [10]. Acidification is not referred to again in the paper and is not implicated in reduced recruitment capacity. What this paper does say is that recruitment capacity (the ability of stocks to produce surviving offspring) has been altered by $3 \%$ of the historical maximum per decade by both environmental changes and overfishing, with overfishing more significant than environmental factors (sea surface temperature and chlorophyll concentration as a surrogate for phytoplankton biomass). Ocean acidification does affect phytoplankton, but this is not discussed in this paper.

Fifth, the paper claims rates of sea level rise 'may soon become exponential' [2]. The source is a University press release about a study of relative sea level rise at selected locations in North America, so changes in both sea level and land surface, which does not mention exponential rise.

Finally, there is the claim 'About half of all plant and animal species in the world's most biodiverse places are at risk of extinction due to climate change' [2]. The source is a press release about a modeling study of selected plant and animal species in the World Wildlife Foundation's 35 biodiversity hotpots. That study predicted that if there was a $4.5^{\circ} \mathrm{C}$ rise in global mean temperature by 2100 , and these species were unable to disperse to more favorable locations, 50\% 'could potentially become locally extinct'.

To highlight these aspects of the paper is not to downplay the seriousness of climate change but to point out the misleading claim that Deep Adaptation is based on science. Climate change is a threat to human livelihoods and demands adaptation through serious investment in health, nutrition, social welfare, renewable energy, carbon sequestration, agriculture, and all the other millennium development goals. The strong sense of conviction in Deep Adaptation that we face inevitable collapse, probable catastrophe and possible extinction' [2] appears to have its roots not in science but in a rich intellectual fascination with decline.

The historian Arthur Herman argues that predictions of the collapse of modern society over the last 150 years have increased in direct proportion to its influence, and for every intellectual who regards it with dread another welcomes it with glee [11]. One classic studys of societal collapse systematically examined the explanations offered for the fall of 17 societies from Rome to Mesoamerica. Having assessed evidence for the influence of environmental catastrophe, resource depletion, invasion, class conflict, disease, religion amongst others, the common factor that emerged was decreasing marginal returns on investment in social and economic complexity [12]. The process of collapse in those societies was usually slow, often perfectly rational, and sometimes resulted in improved circumstances. The collapse predicted in Deep Adaptation is sudden and unavoidable starvation, destruction, migration, disease, and war in our lifetime.

The claim that there is scientific evidence for inevitable nearterm societal collapse is a misuse and abuse of science. Ever since the caravan of Western history pulled out of the Eastern Mediterranean over 2000 years ago it has been trailed by camp followers warning it would all end in tears. And while collapse has been the fate of many societies, science cannot tell us where and when that will happen. Every society that has ever existed has either transformed or collapsed. Which of those occurs, where that happens and how long it takes depends on people and what they chose to do? Contrary to the certainty claimed in Deep Adaptation, the paths to the future are made, not found. Made by people who don't give up.

\section{References}

1. Tsing Z (2019) The climate change paper so depressing it's sending people to therapy.

2. Bendell J (2020a) Deep adaptation: A map for navigating climate tragedy. Occasional Paper 2, Institute for Leadership and Sustainability, University of Cumbria, UK.

3. Deep Adaptation (2020).

4. Bendell (2020b) The worst argument to try to win: Response to criticism of the climate science in deep adaptation.

5. Lenton T, Rockström J, Gaffney O, RahmstorfS, Richardson K, et al. (2019) Climate tipping points: too risky to bet against. Nature 575(7784): 592595.

6. Brook BW, Ellis EC, Buettel JC (2018) What is the evidence for planetary tipping points? In: Effective conservation science: Data not dogma. Kareiva P, Marvier M, Silliman B (Eds.), Oxford University, UK.

7. Wadhams P (2016) A farewell to ice. Oxford University Press, Oxford, UK.

8. Nicholas T, Hall G and Schmidt C (2020) Is deep adaptation flawed science? The Ecologist.

9. Ritchie H, Roser M (2013) Crop yields. Our World In Data.

10. Britten GL, Dowd M, Worm B (2016) Changing recruitment capacity in global fish stocks. PNAS 113(1): 134-139.

11. Herman A (1997) The idea of decline in western history. The Free Press, New York, USA.

12. Tainter J (1988) The collapse of complex societies. Cambridge University Press, Cambridge, UK.

For possible submissions Click below: 